\title{
Assessment of Clinical Pharmacists' Assistance for Patients With Established Cardiovascular Diseases During the COVID-19 Pandemic: Insights From Southern India
}

\author{
Oliver Joel Gona ${ }^{1}$, Ramesh Madhan ${ }^{1 *}$ and Sunil Kumar Shambu ${ }^{2}$ \\ 1 Jagadguru Sri Shivarathreeshwara College of Pharmacy, Jagadguru Sri Shivarathreeshwara Academy of Higher Education \\ and Research (JSS AHER), Mysore, India, ${ }^{2}$ Jagadguru Sri Shivarathreeshwara Medical College and Hospital, Jagadguru Sri \\ Shivarathreeshwara Academy of Higher Education and Research (JSS AHER), Mysore, India
}

OPEN ACCESS

Edited by:

Hendrik Tevaearai Stahel, Bern University Hospital, Switzerland

Reviewed by: Gaetano Ruocco, Regina Montis Regalis Hospital, Italy Harry Staines, Independent Researcher, York, United Kingdom

*Correspondence:

Ramesh Madhan mramesh@jssuni.edu.in

Specialty section:

This article was submitted to General Cardiovascular Medicine, a section of the journal Frontiers in Cardiovascular Medicine

Received: 28 August 2020 Accepted: 10 November 2020 Published: 03 December 2020

Citation: Gona OJ, Madhan R and Shambu SK (2020) Assessment of Clinical Pharmacists' Assistance for Patients With Established Cardiovascular Diseases During the COVID-19 Pandemic: Insights From Southern doi: 10.3389/fcrm.2020.599807
Objectives: We aimed to assess the clinical pharmacist-initiated telephone-based patient education and self-management support for patients with cardiovascular disease during the nationwide lockdown during COVID-19 pandemic.

Methods: A prospective single-center telephone-based cross-sectional study was conducted among patients at the Cardiology Department and its speciality clinic at a 1,800-bed tertiary care hospital in Southern India. A validated 8-item clinical pharmacist aided on-call questionnaire with two Domains was administered during and after lockdown (15 March and 8 June 2020). Clinical pharmacist-provided educational assistance on self-management practices were in accordance with the guidelines of Indian Council of Medical Research (ICMR) and World Health Organization. Comparisons was performed using sign test and association of responses were analyzed using the Goodman and Kruskal's gamma test. All the tests were two-tailed, $p<0.05$ was considered to be statistically significant.

Results: Of the 1,080 patients, 907 consented with a response rate of (83.9\%) and 574 (96.36\%) patients were analyzed post-intervention. Majority of the patients were male (54.7\%) and had Acute Coronary Syndrome [NSTEMI (42.10\%), STEMI (33.92\%) and Unstable Angina (9.86)]. The majority of subjects had at least two co-morbid conditions [(Type II Diabetes (48.33\%), Hypertension (50.11\%)] and were rural population (82.5\%) as self-employed (43.1\%) with a middle-class economy (31.6\%). In the Domain-1 of checklist the awareness toward complications caused by COVID-19 in cardiovascular diseases $(Z=-19.698, p=0.000)$ and the importance of universal safety precautions enhanced after clinical pharmacist assistance $[(Z=$ -8.603, $p=0.000)$ and $(Z=-21.795, p=0.000)$ ]. In Domain-II of checklist there was a significant improvement in patients awareness toward fatal complications caused by COVID-19 $(Z=-20.543, p=0.000)$, maintenance of self-hygiene ( $Z$ $=-19.287, p=0.000)$, practice of universal safety precautions $(Z=-16.912, p$ $=0.000)$ and self-isolation $(Z=-19.545, p=0.000)$. The results of our study population varied from baseline evaluation $(41.7 \%, n=907)$ to post-intervention (95\%, $n=574)$ based on Literacy, employment status and economic status. 


\begin{abstract}
Conclusions: The proactive role of clinical pharmacists in providing instructional services in collaboration with cardiologist during the pandemic circumstances increased patients understanding and mitigated infection exposure among patients, health care professionals and also assuring the continuity of care in patients with established cardiovascular diseases.
\end{abstract}

Keywords: COVID-19, cardiovascular diseases, clinical pharmacist, SARS-CoV- 2, corona virus 19

\section{INTRODUCTION}

In the last two decades, clustering and incidence of severe acute respiratory infections are one of the major threats to public health. Coronavirus disease (COVID-19) was first recorded in Wuhan, China, by the end of December 2019. Since then, COVID-19 has rapidly spread around the world. The COVID19 was declared as a global pandemic on 11th March 2020 by the World Health Organization. COVID-19 has a major impact on public health and has a direct or indirect impact on social and economic activities. The exponential increase in the number of patients with COVID-19 in the past 6 months has overwhelmed health-care systems across the world. This is due to an inadequate understanding of the dynamic interplay of shifting epidemiology, publicity, pandemic prevention strategies, risk identification, and public health behavior (1). Cardiovascular disease is common comorbidity observed in patients infected with SARS or MERS (10 and 30\% prevalence, respectively) (2). Currently, there is no promising evidence from randomized clinical trials (RCTs) that any potential therapy improves outcomes in patients with either suspected or confirmed COVID-19. Neither clinical trial data is supporting any prophylactic therapy.

The pre-existing cardiovascular disease seems to be linked with worse outcomes and increased risk of death in patients with COVID-19. Patients requiring intensive treatment had a significantly higher prevalence of chronic health conditions such as diabetes, cardiovascular and cerebrovascular disease (3). Moreover, COVID-19 itself can cause induce myocardial injury, arrhythmia, acute coronary syndrome and venous thromboembolism (4). Providing clinical care for patients with chronic cardiovascular disease and other comorbidities during pandemic times is challenging. Telehealth is an ideal platform to deliver clinical care during disasters and pandemics. Telemedicine negated the risk of COVID-19 exposure or transmission (5). In India, providing healthcare is a challenge, telemedicine ensures the safety of patients and health workers, especially when there is a risk of infection (6). India's digital health policy advocates the use of digital tools and focuses significantly on the use of telemedicine services, particularly at the grassroots level in the health and wellness Centers, where a mid-level provider/health worker can connect patients to doctors through technology platforms to provide timely and best possible care (7).

Citizens can make informed choices, defend themselves and comply with prescribed practices by focusing on what can be done during COVID-19 and when adequate resources are accessible, easily understood and communicated via reliable and accessible networks (8). Therefore, through collaboration between clinical pharmacist and cardiologist, we aimed to provide educational assistance regarding self-management practices in patients with existing cardiovascular diseases to mitigate exposure to COVID-19 infection.

\section{METHODS}

\section{Study Design and Participants}

A prospective single-center telephone-based cross-sectional study was conducted among patients at the Cardiology Department and its speciality clinic at a 1,800-bed tertiary care hospital in Southern India serving 37 specialities. A validated 8 -item clinical pharmacist aided on-call questionnaire with two Domains (Table 1) was administered during and after lockdown (15 March and 8 June 2020). Majority of the participants with acute coronary syndrome were the subset population of an ongoing clinical study and are currently being followed up. Clinical pharmacist-provided educational assistance on selfmanagement practices was in accordance with the guidelines of Indian Council of Medical Research (ICMR) and World Health Organization.

\section{Reliability and Validity of the Questionnaire}

Initially, the questionnaire was validated by selected faculty and research team using facial and content validation methods to ensure readability. To assess overall reliability, the internal consistency of individual items in each questionnaire domain was examined by the researchers. The questionnaire consists of two domains and eight questions pertaining to awareness and knowledge of subjects toward COVID-19. Each question consists of two responses which was scored as Yes is 1 and No is 2. The score for the questionnaire range between 8 and 16, for the purpose of identifying the status of awareness and knowledge, participants are divided into high knowledge (8-12) and low knowledge (13-16) categories that has been derived by cumulative score. Finally, the survey questionnaire was administered to patients by a clinical pharmacist to facilitate better understanding. Higher score $(>12)$ for the questionnaire indicates that patients have lack of awareness and knowledge which indicates the need for educational assistance. This telemedicine questionnaire of clinical pharmacists to assess awareness and knowledge regarding COVID-19 for patients with established cardiovascular diseases was self-developed with scoring, there are no references identified to cite this conjecture. 
TABLE 1 | 8-item telemedicine questionnaire checklist of clinical pharmacists to assess awareness and knowledge regarding COVID-19 for patients with established cardiovascular diseases.

\begin{tabular}{|c|c|c|c|}
\hline S no & Questions & Response & Score \\
\hline \multicolumn{4}{|c|}{ Domain-I: Assessment of awareness } \\
\hline \multirow[t]{2}{*}{1} & Are you aware of the spread and impact of Novel corona virus 2019? & YES & 1 \\
\hline & & NO & 2 \\
\hline \multirow[t]{2}{*}{2} & Are you aware of the complications caused by Novel corona virus among patients with cardiovascular diseases? & YES & 1 \\
\hline & & NO & 2 \\
\hline \multirow[t]{2}{*}{3} & Are you aware of your present and past medical history & YES & 1 \\
\hline & & NO & 2 \\
\hline \multirow[t]{2}{*}{4} & Are you aware of the importance of universal safety precautions to prevent getting infected from Novel corona virus? & YES & 1 \\
\hline & & NO & 2 \\
\hline \multicolumn{4}{|c|}{ Domain-II: Assessment of knowledge } \\
\hline \multirow[t]{2}{*}{5} & $\begin{array}{l}\text { Do u know that Novel corona virus cause (SARS-nCoV-19) life threatening fatal complications among patients with cardiovascular } \\
\text { complications and other co-morbid conditions? }\end{array}$ & YES & 1 \\
\hline & & NO & 2 \\
\hline \multirow[t]{2}{*}{6} & $\begin{array}{l}\text { Do you know that self-isolation and maintenance of hygiene can aid in preventing infection from Novel corona virus cause } \\
\text { (SARS-CoV-2)? }\end{array}$ & YES & 1 \\
\hline & & NO & 2 \\
\hline \multirow[t]{2}{*}{7} & Do you know how to follow universal safety precautions to prevent getting infected from Novel corona virus? & YES & 1 \\
\hline & & NO & 2 \\
\hline \multirow[t]{2}{*}{8} & Do you know that self-quarantine is a procedure followed by people who are at risk during epidemic? & YES & 1 \\
\hline & & NO & 2 \\
\hline
\end{tabular}


diseases by a clinical pharmacist through telephone.

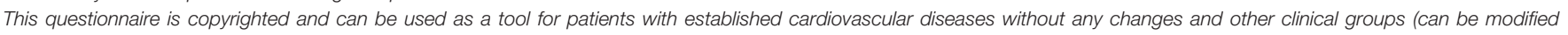
accordingly) to assess awareness and knowledge about COVID-19 or SARS nCov-II infection.

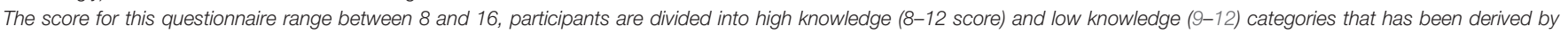
cumulative scores. Higher score (>12) for this questionnaire indicates that patients have lack of Awareness and Knowledge which indicates the need for educational assistance.

\section{Sampling Method}

This study followed a non-probability sampling method among the target population (subjects with established cardiovascular diseases at a tertiary care hospital).

\section{Outcome}

The primary outcome of the study is to identify the impact of the clinical pharmacist-initiated educational guidance on COVID19 pandemic among patients with established cardiovascular disease. The secondary outcome is to ensure continuity of care and compliance with the prescribed drugs.

\section{Statistical Analysis}

Data were entered in MS Office Excel 2019 and analyzed using the IBM SPSS Statistics Version 25. Continuous variables were presented as mean \pm standard deviation (SD). Categorical variables were presented as absolute numbers and percentages. Comparisons between baseline and post assistance scores among the individuals were performed using sign test, Association of Responses with socio-demographic variables were analyzed using the Goodman and Kruskal's gamma test. All tests were two-tailed, $p<0.05$ was considered to be statistically significant.

\section{RESULTS}

Of the 1,080 patients contacted by telephone, the response rate at the baseline was 907 (83.9\%) and 574 (63.28\%) post-intervention. The majority $(54.7 \%)$ of the study population were male and had at least two co-morbid conditions (44.56\%) in the age group (61-80 years) (Table 2). The patients in the study had Acute Coronary Syndrome [NSTEMI (42.10\%), STEMI (33.92\%) and UA (9.86\%)] followed by associated comorbidities as described in Table 3. The questionnaire developed was administered during and after nationwide lockdown. In the Domain-1 the patients were aware of the spread of COVID-19 $(p=0.000)$ and their current condition $(p=0.000)$. However, majority of them were not aware of the complications caused by COVID-19 among patients with cardiovascular diseases $(Z=-19.698, p$ $=0.000)$ and the importance of universal safety precautions, their awareness enhanced after clinical pharmacist assistance $[$ (Yes $=85.01$ vs. $98.08 \%$, No $=14.99$ vs. $1.92 \%, Z=-8.603$, $p=0.000)$ and (Yes $=11.84$ vs. $94.94 \%$, No $=88.15$ vs. $5.05 \%, Z=-21.795, p=0.000)$ ]. In Domain-II regarding knowledge aspect majority of the patient's knowledge improved regarding fatal complications caused by COVID 19 (Yes $=22.12$ vs. $95.98 \%$, No $=77.87$ vs. $4.01 \%, Z=-20.543$, $p=0.000$ ), the process of self-isolation, maintenance of self-hygiene (Yes 
TABLE 2 | Descriptive Summary of Demographics $(N=574)$.

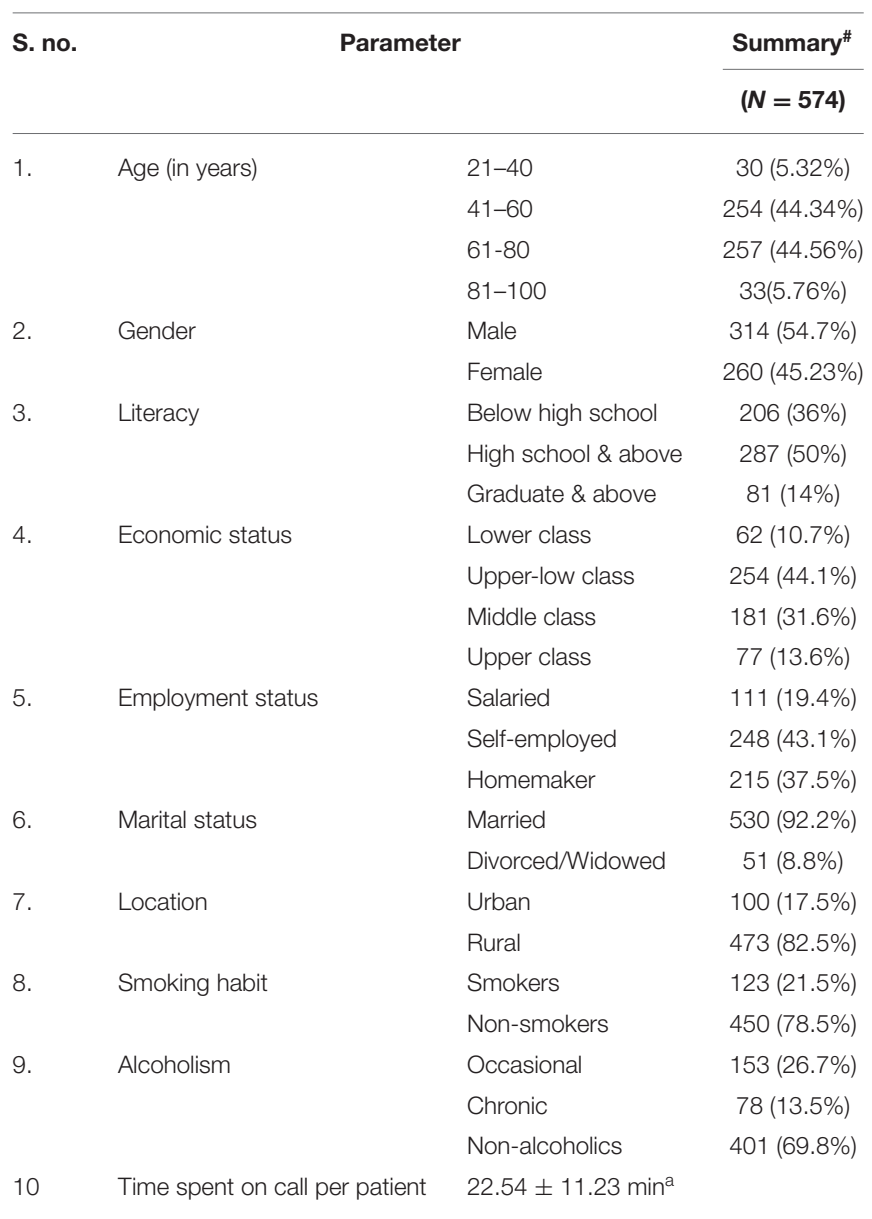

\#Data represented as number (proportion), adata represented as Mean $\pm S D, S D$ : Standard Deviation.

$=33.97$ vs. $99.12 \%$, No $=66.02$ vs. $0.88 \%, Z=-19.287, p$ $=0.000)$, the importance of universal safety precaution (Yes $=$ 44.94 vs. $94.94 \%$, No $=55.06$ vs. $5.06 \%, Z=-16.912, p=$ 0.000 ) and regarding self-quarantine (Yes $=25.08$ vs. $91.98 \%$, No $=74.91$ vs. $8.02 \%, Z=-19.545, p=0.000)$ depicted in Table 4. The individual responses of the patients for every question at baseline was evaluated to correlate the association of sociodemographic variables with awareness and knowledge which demonstrated that the responses of the patients varied based on Literacy, employment status and economic status as represented in Table 5.

\section{DISCUSSION}

Pandemics and epidemics are a widespread problem then and now as COVID-19. During such periods, people in the community face several challenges. Lack of awareness and consciousness often leads to an uneasy attitude which could adversely affect the patients with established cardiovascular complications. Different stakeholders in their respective countries are working together to "flatten the curve" by joint
TABLE 3 | Clinical parameters.

\begin{tabular}{llcc}
\hline S. no. & Parameter & \multicolumn{2}{l}{ Summary\# } \\
\cline { 3 - 4 } & & \multicolumn{2}{c}{$(\boldsymbol{N}=\mathbf{5 7 4})$} \\
\hline 1. & Acute coronary syndrome (ACS) & UA & $57(9.86 \%)$ \\
& & NSTEMl & $242(42.10 \%)$ \\
& & STEMI & $195(33.92 \%)$ \\
2. & Venous thromboembolism (VTE) & DVT & $48(8.4 \%)$ \\
& & PE & $33(5.8 \%)$ \\
3. & T2DM & $277(48.33 \%)$ \\
4. & HTN & $288(50.11 \%)$ \\
5. & Kidney disease & $72(12.56 \%)$ \\
6. & T2DM + HTN & $292(50.86 \%)$ \\
7. & COPD & $211(36.73 \%)$ \\
8. & Depression & $22(3.8 \%)$ \\
9. & Atrial fibrillation & $17(2.9 \%)$ \\
\hline
\end{tabular}

T2DM, Type 2 Diabetes Mellitus; HTN, Hypertension; COPD, Chronic obstructive pulmonary disease; UA, Unstable angina; NSTEMI, non-ST segment elevation myocardial infarction; STEMI, ST-Elevation Myocardial Infarction.

"Data represented as number (proportion).

prevention initiatives led by the WHO. With a practically sufficient global lockdown, Pharmacists appear to be the first contact point for meeting the health requirements of the public (8).

We studied the role of clinical pharmacists' assistance for patients with established cardiovascular diseases during the COVID-19. The principal findings in our study at initial assessment were (1) Most of the patients were aware of their medical condition (CVD and comorbidities), (2) Most of the patients were aware of SARS-CoV-2 (COVID-19) infection, (3) majority of the patients were unaware of fatal complications caused by COVID-19 and association of COVID severity with CVD and comorbidities, (4) most of them were unaware of the importance of universal safety precautions, (5) majority of them don't know that self-quarantine is a procedure followed by people who are at risk during the epidemic.

Pharmacists continue to play their role in promoting continuity of pharmaceutical care, as well as supporting governments for disseminating information on precautions related to COVID-19 spread (13). Pharmacists are an integral part of health care performing exceptional roles in past pandemics and health crises, with some, such as Ebola and Zika, posing global health security risks (9). In this study after assessing the awareness and knowledge we provided educational assistance which helped our patients to gain (1) knowledge regarding fatal complications caused by COVID 19, (2) the process of self-isolation, (3) maintenance of self-hygiene, (4) the importance of universal safety precaution and (5) regarding self-quarantine practice. The Chinese Centre for Disease Control and Prevention recently published the largest COVID-19 case series in mainland China; the overall fatality rate was $2.3 \%$ (1,023 deaths among 44,672 confirmed cases), but the mortality rate in 
TABLE 4 | Comparison of on call checklist responses before and after the clinical pharmacist assistance/intervention.

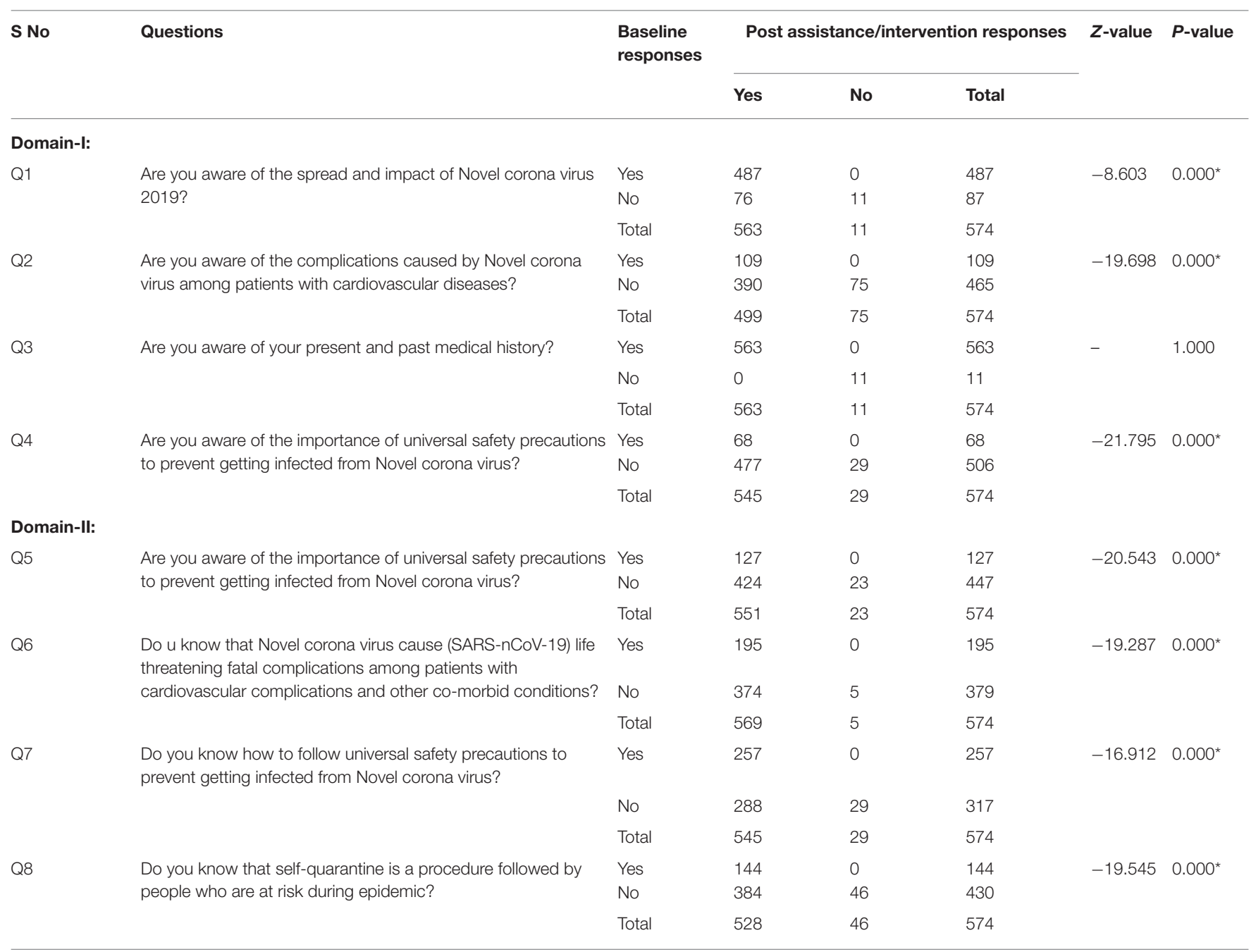

${ }^{*}$ Statistically significant $p$-value $(2$-tailed, < 0.05) has been obtained by performing Sign test.

patients with underlying CVD reached $10.5 \%$ (10). However, these results emphasize the potential risk of fatality in our patients with established cardiovascular disease and provide evidence regarding the need for intensive treatment on the infection (11).

The other measure which has been mentioned a lot in recent weeks is hand hygiene. The World Health Organization (WHO) regards handwashing with soap and water and friction with hydroalcoholic gel as the most effective measures for the prevention of infections and antimicrobial resistance (12). Research in major public universities following the H1N1 influenza pandemic reported inadequate compliance with preventive measures, such as residence at home when the virus is ill to prevent transmission in 2009 linked to the results of this study (14). Researchers can work with public agencies/health departments to set up information and awareness centers through participatory groups that may have significant population effects. Our study helped to implement preventive measures, such as isolation, quarantine and community confinement, early identification of cases, social assistance and the provision of patient-specific instructions.

As a consequence of COVID-19, the need for social distancing forced us to use all the resources in our toolbox, and telehealth is one of them that accelerated its adoption globally (15). Telehealth strategies should be encouraged with a view to increasing access and providing care to the patients with chronic diseases to promote continuity of their care which made us adapt the new normal practices. We need to make a conscious effort to avoid any possible worsening of the digital divide, and the government needs to take that responsibility in this case (16).

What was wonderful about it was during this pandemic when our patients are generally considered to be at greater risk of having more severe COVID-19 disease and when they have been asked to stay at home, through virtual 
TABLE 5 | Association of baseline responses with socio-demographic variables among study participants.

\begin{tabular}{|c|c|c|c|c|c|c|c|c|c|c|c|c|c|c|c|c|c|}
\hline \multirow[t]{2}{*}{ Question } & \multirow[t]{2}{*}{ Response } & \multicolumn{5}{|c|}{ Literacy } & \multicolumn{5}{|c|}{ Employment status } & \multicolumn{5}{|c|}{ Economic status } & \multirow[b]{2}{*}{$p$-value } \\
\hline & & 1 & 2 & 3 & Gamma & $p$-value & 1 & 2 & 3 & Gamma & $p$-value & 1 & 2 & 3 & 4 & Gamma & \\
\hline \multirow[t]{2}{*}{ Q1 } & Yes & 138 & 270 & 79 & -0.776 & $0.000^{*}$ & 83 & 230 & 177 & -0.043 & 0.693 & 55 & 223 & 153 & 56 & 0.252 & $0.008^{\star}$ \\
\hline & No & 68 & 17 & 2 & & & 28 & 18 & 38 & & & 7 & 31 & 28 & 21 & & \\
\hline \multirow[t]{2}{*}{ Q2 } & Yes & 13 & 70 & 26 & -0.532 & $0.000^{*}$ & 20 & 49 & 40 & 0.000 & 0.999 & 35 & 208 & 157 & 66 & -0.329 & $0.000^{*}$ \\
\hline & No & 193 & 217 & 55 & & & 91 & 199 & 175 & & & 27 & 46 & 24 & 11 & & \\
\hline \multirow[t]{2}{*}{ Q3 } & Yes & 198 & 285 & 80 & -0.556 & $0.055^{\star}$ & 99 & 233 & 197 & -0.042 & 0.761 & 46 & 246 & 175 & 70 & -0.310 & $0.047^{\star}$ \\
\hline & No & 8 & 2 & 1 & & & 12 & 15 & 18 & & & 16 & 8 & 6 & 7 & & \\
\hline \multirow[t]{2}{*}{ Q4 } & Yes & 4 & 32 & 32 & -0.767 & $0.000^{*}$ & 26 & 20 & 22 & 0.266 & $0.021^{*}$ & 38 & 227 & 171 & 70 & -0.465 & $0.000^{*}$ \\
\hline & No & 202 & 255 & 49 & & & 85 & 228 & 193 & & & 24 & 27 & 10 & 7 & & \\
\hline \multirow[t]{2}{*}{ Q5 } & Yes & 21 & 70 & 36 & -0.520 & $0.000^{*}$ & 32 & 41 & 54 & -0.008 & 0.925 & 44 & 38 & 26 & 19 & 0.336 & $0.000^{*}$ \\
\hline & No & 185 & 217 & 45 & & & 79 & 207 & 161 & & & 18 & 216 & 155 & 58 & & \\
\hline \multirow[t]{2}{*}{ Q6 } & Yes & 51 & 102 & 42 & -0.323 & $0.000^{*}$ & 24 & 74 & 97 & -0.337 & $0.000^{*}$ & 29 & 101 & 106 & 41 & -0.196 & $0.003^{*}$ \\
\hline & No & 155 & 185 & 39 & & & 87 & 174 & 118 & & & 33 & 153 & 75 & 36 & & \\
\hline \multirow[t]{2}{*}{ Q7 } & Yes & 67 & 175 & 15 & -0.076 & 0.275 & 47 & 113 & 97 & -0.025 & 0.720 & 26 & 77 & 102 & 52 & -0.379 & $0.000^{*}$ \\
\hline & No & 137 & 113 & 67 & & & 64 & 135 & 118 & & & 36 & 177 & 79 & 25 & & \\
\hline \multirow[t]{2}{*}{ Q8 } & Yes & 48 & 82 & 14 & 0.014 & 0.864 & 22 & 63 & 59 & -0.114 & 0.157 & 19 & 53 & 54 & 7 & 0.094 & 0.222 \\
\hline & No & 158 & 205 & 67 & & & 89 & 185 & 156 & & & 43 & 201 & 127 & 70 & & \\
\hline
\end{tabular}

*Statistically significant p-value has been derived from application of Goodman and Kruskal's gamma test.

Literacy: 1: Below high school, 2: High school \& above, 3: Graduate \& above. Employment:1: Salaried, 2: Self-employed, 3: Homemaker. Economic status: 1: Lower class, 2: Upper-Low class, 3: Middle class, 4: Upper class. 
visits, we are still able to maintain their continuity of care, evaluate their COVID-19 awareness and knowledge, and provide instructional assistance and mitigate their exposure to infection. Overall, the results reflect what might develop into a new standard of future health care, particularly during contagious outbreaks (17). In this difficult time, hopelessness is the mother of acceptance, virtual practices have become a new normal. But hopefully, as we emerge from this pandemic, the telemedicine infrastructure will remain and benefit those in need.

\section{Strengths and Limitations}

During the times of stretched clinical resources due to COVID19, our research results helped to add new ways to reduce COVID-19 spread in patients with established cardiovascular diseases. Although our study is a single-center study involving a clinical pharmacist, despite its limitations, the results in our study suggest that the extended role of the clinical pharmacist may also be beneficial to other clinical groups. In addition, more awareness amongst the study patients could also be attributed to govt initiated awareness programmes on COVID-19 (18). The results of this study may not be generalizable beyond India due to differences in clinical pharmacist practice worldwide.

\section{CONCLUSIONS}

The clinical pharmacist may, however, play a pro-active role in promoting patient-specific treatment decisions by serving as a resource for physicians and other health care professionals to mitigate adverse events caused by SARS nCoV-2 infection in

\section{REFERENCES}

1. Taggart J, Williams A, Dennis S, Newall A, Shortus T, Zwar N, et al. A systematic review of interventions in primary care to improve health literacy for chronic disease behavioral risk factors. BMC Family Pract. (2012) 13:49. doi: 10.1186/1471-2296-13-49

2. Madjid M, Safavi-Naeini P, Solomon SD, Vardeny O. Potential effects of coronaviruses on the cardiovascular system: a review. JAMA Cardiol. (2020) 5:831-40. doi: 10.1001/jamacardio.2020.1286

3. Zhou F, Yu T, Du R, Fan G, Liu Y, Liu Z, et al. Clinical course and risk factors for mortality of adult inpatients with COVID-19 in Wuhan, China: a retrospective cohort study. Lancet. (2020) 395:1054-62. doi: 10.1016/S0140-6736(20)30566-3

4. Nishiga M, Wang DW, Han Y, Lewis DB, Wu JC. COVID-19 and cardiovascular disease: from basic mechanisms to clinical perspectives. Nat Rev Cardiol. (2020) 20:1-6. doi: 10.1038/s41569-0200413-9

5. Monaghesh E, Hajizadeh A. The role of telehealth during COVID19 outbreak: a systematic review based on current evidence. BMC Pub Health. (2020) 20:1193. doi: 10.1186/s12889-02009301-4

6. Shadmi E, Chen Y, Dourado I, Faran-Perach I, Furler J, Hangoma P, et al. Health equity and COVID-19: global perspectives. Int J Equity Health. (2020) 19:1-6. doi: 10.1186/s12939-020-01218-z

7. Telemedicine Practice Guidelines. Available online at: https://www.mohfw.gov. in/pdf/Telemedicine.pdf (accessed April 16, 2020). patients with established cardiovascular disease. The enhanced role of clinical pharmacists in providing instructional services should mitigate infection transmission during the COVID19 pandemic.

\section{DATA AVAILABILITY STATEMENT}

The original contributions presented in the study are included in the article/supplementary materials, further inquiries can be directed to the corresponding author/s.

\section{ETHICS STATEMENT}

The institutional ethics committee has approved this study and participants have been informed of the purpose of the study before participating and voluntary consent is obtained virtually. All procedures performed in this study involving human participants were consistent with the Declaration of Helsinki 1964 and its subsequent amendments or comparable ethical standards.

\section{AUTHOR CONTRIBUTIONS}

All authors listed have made a substantial, direct and intellectual contribution to the work, and approved it for publication.

\section{ACKNOWLEDGMENTS}

The authors would like to thank the Department of Cardiology and Department of Clinical Pharmacy, JSS Hospital and JSS College of Pharmacy for facilitating the study.
8. Okan O, Bollweg TM, Berens EM, Hurrelmann K, Bauer U, Schaeffer D. Coronavirus-related health literacy: a cross-sectional study in adults during the COVID-19 infodemic in Germany. Int J Environ Res Pub Health. (2020) 17:5503. doi: 10.3390/ijerph17155503

9. Li H, Zheng S, Liu F, Liu W, Zhao R. Fighting against COVID-19: innovative strategies for clinical pharmacists. Res Soc Administ Pharm. (2020). doi: 10.1016/j.sapharm.2020.04.003

10. Wu Z, McGoogan JM. Characteristics of and important lessons from the coronavirus disease 2019 (COVID-19) outbreak in China: summary of a report of 72314 cases from the Chinese center for disease control and prevention. JAMA. (2020) 323:1239-42. doi: 10.1001/jama.202 0.2648

11. Guo T, Fan Y, Chen M, Wu X, Zhang L, He T, et al. Cardiovascular implications of fatal outcomes of patients with coronavirus disease 2019 (COVID-19). JAMA Cardiol. (2020) 5:811-8. doi: 10.1001/jamacardio.2020.1017

12. Safety WP, World Health Organization. WHO Guidelines on Hand Hygiene in Health Care. Geneva: World Health Organization (2009).

13. Bukhari N, Rasheed H, Nayyer B, Babar ZU. Pharmacists at the frontline beating the COVID-19 pandemic. J Pharmaceut Policy Practice. (2020) 13:8. doi: 10.1186/s40545-020-00210-w

14. Morens DM, Taubenberger JK, Harvey HA, Memoli MJ. The 1918 influenza pandemic: lessons for 2009 and the future. Crit Care Med. (2010) 38(Suppl. 4):e10. doi: 10.1097/CCM.0b013e3181ceb25b

15. Fisk M, Livingstone A, Pit SW. Telehealth in the context of COVID19: Changing Perspectives in Australia, the United Kingdom, and the 
United States. J Med Internet Res. (2020) 22:e19264. doi: 10.2196/ 19264

16. Ramsetty A, Adams C. Impact of the digital divide in the age of COVID-19. J Am Med Inform Associat. (2020) 27:1147-8. doi: 10.1093/jamia/ocaa078

17. Tahan HM. Essential case management practices amidst the novel coronavirus disease 2019 (COVID-19) crisis: part 2: end-of-life care, workers' compensation case management, legal and ethical obligations, remote practice, and resilience. Prof Case Manage. (2020). doi: 10.1097/NCM.0000000000000455

18. World Health Organization. Coronavirus Disease 2019 (COVID-19) Situation Report (2020). p. 72.
Conflict of Interest: The authors declare that the research was conducted in the absence of any commercial or financial relationships that could be construed as a potential conflict of interest.

Copyright (C) 2020 Gona, Madhan and Shambu. This is an open-access article distributed under the terms of the Creative Commons Attribution License (CC BY). The use, distribution or reproduction in other forums is permitted, provided the original author(s) and the copyright owner(s) are credited and that the original publication in this journal is cited, in accordance with accepted academic practice. No use, distribution or reproduction is permitted which does not comply with these terms. 